\title{
The human microbiome
}

\author{
Bryan Coburn MD PhD, David S. Guttman PhD
}

The healthy microbiome varies substantially across individuals and groups

The human microbiome (glossary in Appendix 1, available at www.cmaj.ca/ lookup/suppl/doi:10.1503/cmaj.141072 /-/DC1) comprises hundreds of previously known and newly discovered microbial species living in distinct communities adapted to specific anatomic sites. ${ }^{1}$ In healthy adults, these diverse communities vary between individuals and anatomic sites, and from the first years of life. ${ }^{1}$

Pathologic perturbation of the microbiome is increasingly recognized as an important correlate of infectious and noninfectious diseases

Disturbances in the microbiome (dysbiosis) are associated with the development of diverse conditions, such as Clostridium difficile infection, inflammatory bowel disease, obesity, psoriasis and allergies; ${ }^{3}$ however, some of these associations may not be causal.

CMAJ invites submissions to "Five things to know about ..." Submit manuscripts online at http://mc.manuscriptcentral. com/cmaj

\section{The human microbiome is essential for healthy development, metabolism} and immunity

The normal microbiome has many healthy interactions with the host in the absence of disease. For example, enteric microbiota are involved in the metabolism of ingested nutrients and priming of the host immune system, and skin and mucosal microbiota can competitively inhibit colonization by pathogens, such as Staphylococcus aureus. ${ }^{2}$

Host behaviours and external factors, such as diet, exercise and medications, can influence the human microbiome

Diet composition measurably and reproducibly alters the human microbiome. Unlike plant-based diets, diets that are exclusively animal-based cause shortterm changes in the composition of the fecal microbiome and metabolites associated with inflammatory and neoplastic disease. ${ }^{4}$ The use of antibiotics is associated with substantial loss of richness and diversity in the fecal microbiome that can last days to months, and the microbiome may never fully recover after the treatment ends. 5

\section{References}

1. Human Microbiome Project Consortium. Structure, function and diversity of the healthy human microbiome. Nature 2012;486:207-14.

2. Bäckhed F, Fraser CM, Ringel Y, et al. Defining a healthy human gut microbiome: current concepts, future directions, and clinical applications. Cell Host Microbe 2012;12:611-22.

3. Cho I, Blaser MJ. The human microbiome: at the interface of health and disease. Nat Rev Genet 2012; 13:260-70.

4. David LA, Maurice CF, Carmody RN, et al. Diet rapidly and reproducibly alters the human gut microbiome. Nature 2014;505:559-63.

5. Dethlefsen L, Relman DA. Incomplete recovery and individualized responses of the human distal gut microbiota to repeated antibiotic perturbation. Proc Natl Acad Sci U S A 2011;108(Suppl 1):4554-61.

6. van Nood E, Vrieze A, Nieuwdorp M, et al. Duodenal infusion of donor feces for recurrent Clostridium difficile. N Engl J Med 2013;368:407-15.
Therapeutic manipulation of the human microbiome using microbiome transplantation or probiotics is a promising treatment for a variety of diseases

In a randomized controlled trial involving patients who had a relapse of $C$. difficile infection after at least one course of treatment with antibiotics, transplantation of stool from healthy donors to these patients was found to be an effective treatment, with $81 \%$ efficacy after a single administration. ${ }^{6}$ Probiotics have the potential to affect the structure and function of the microbiome, but the efficacy and durability of their effects varies by disease and probiotic formulation. Treating infectious and noninfectious diseases using microbiota transplantation is an area of active and expanding investigation.

Competing interests: None declared.

This article has been peer reviewed.

Affiliations: Cell and Systems Biology, School of Graduate Studies (Coburn, Guttman); Centre for the Analysis of Genome Evolution and Function (Guttman), University of Toronto, Toronto, Ont.

Correspondence to: Bryan Coburn, bryan.coburn @utoronto.ca

CMAJ 2015. DOI:10.1503/cmaj.141072 